\title{
Per-Phase and 3-Phase Optimal Coordination of Directional Overcurrent Relays Using Genetic Algorithm
}

\author{
Ronald C. Matthews *, Trupal R. Patel, Adam K. Summers (D), Matthew J. Reno and Shamina Hossain-McKenzie \\ Sandia National Laboratories, P.O. Box 5800 MS 1033, Albuquerque, NM 87185, USA; tpatel@sandia.gov (T.R.P.); \\ asummer@sandia.gov (A.K.S.); mjreno@sandia.gov (M.J.R.); shossai@sandia.gov (S.H.-M.) \\ * Correspondence: rcmatth@sandia.gov; Tel.: +1-505-845-7608
}

Citation: Matthews, R.C.; Patel, T.R.; Summers, A.K.; Reno, M.J.;

Hossain-McKenzie, S. Per-Phase and 3-Phase Optimal Coordination of Directional Overcurrent Relays Using Genetic Algorithm. Energies 2021, 14, 1699. https://doi.org/10.3390/ en14061699

Academic Editor: Tek Tjing Lie

Received: 11 January 2021

Accepted: 11 March 2021

Published: 18 March 2021

Publisher's Note: MDPI stays neutral with regard to jurisdictional claims in published maps and institutional affiliations.

Copyright: (c) 2021 by the authors. Licensee MDPI, Basel, Switzerland. This article is an open access article distributed under the terms and conditions of the Creative Commons Attribution (CC BY) license (https:// creativecommons.org/licenses/by/ $4.0 /)$.

\begin{abstract}
Penetration of the power grid by renewable energy sources, distributed storage, and distributed generators is becoming increasingly common. Increased utilization of these distributed energy resources (DERs) has given rise to additional protection coordination concerns, particularly where they are utilized in an unbalanced manner or where loading among phases is unbalanced. Digital relays such as the SEL-751 (produced by Schweitzer Engineering Laboratories, Pullman, WA, USA) series have the capability of being set on a per-phase basis. This capability is underutilized in common practice. Additionally, in optimization algorithms for determining relay settings, the timeovercurrent characteristics (TOCs) of relays are generally not treated as variables and are assigned before running the optimization algorithm. In this paper, TOC options themselves are treated as discrete variables to be considered in the optimization algorithm. A mixed integer nonlinear programming problem (MINLP) is set up where the goal is to minimize relay operating times. A genetic algorithm (GA) approach is implemented in MATLAB where two cases are considered. In the first case, the TOC and Time dial setting (TDS) of each relay is set on a three-phase basis. In the second case, per-phase settings are considered. Relay TDSs and TOCs are both considered as simultaneous discrete control variables. Despite the stochastic nature of using per-phase settings for unbalanced systems is found to generally allow for shorter operating times. However, for relatively balanced systems, it is best to use three-phase settings if computation time is of importance.
\end{abstract}

Keywords: inverse time overcurrent relay; genetic algorithm (GA); time overcurrent characteristic (TOC); time dial settings (TDS); coordination time interval (CTI); per-phase relay coordination; three-phase relay coordination

\section{Introduction}

The complexity of the power grid is rapidly increasing with the more common usage of DERs and microgrid structures containing DERs which are capable of both delivering and absorbing energy [1,2]. DERs placed at the end of a radial line can cause issues with relays, especially if the DERs can discharge large amounts of energy upstream to the main grid [3]. The main objective of relay coordination is to set the protection to operate as fast as possible for faults when acting as the primary protection and to operate with sufficient delay when acting as a backup. Coordination ensures that the protective device nearest to the fault operates first and the backup device operates only if the primary has failed to isolate the fault.

Traditionally, in a radial distribution system, the coordination of overcurrent protection is based on the comparisons of the operating times of the relays in response to the various levels of fault currents. Generally, the maximum and minimum fault current observed by the relays are used for comparison [4]. To advance coordination capabilities modern digital relays are now designed with the capability of changing TOCs on demand. Additionally, if spot generation from renewable energy sources such as photovoltaic (PV) becomes more prevalent or loads are highly unbalanced, per-phase coordination settings available on 
some digital relays can allow for further enhancements in coordination capabilities. If the DERs are single-phase and capable of moderate to high generation levels, traditional relay settings may become invalidated. Thus, both settings based on per-phase considerations when available and three-phase traditional settings need to be considered.

Local area power systems may require that microgrids be able to operate in islanded mode [5]. This forces any microgrid structure to have within it at least one DER capable of generating power and possibly back feeding energy into the main grid across the point of common coupling (PCC) between the grid and microgrid. Adaptive protection as discussed in Refs. [6-10] exploits the flexibility of digital relays by programming them to change their settings; change their characteristics; and re-coordinate in response to the most recently observed state of the system. In the work presented paper, loading is considered to determine pickup settings of relays. Adaptive protection and associated issues such as loss of communication are not discussed here. These topics are left for future work. However, the proposed methodology provides an intermediate step in the move towards adaptive protection. In this paper, radial lines with DERs present are considered. As the focus of this paper is overcurrent relays, loops are not considered.

This paper is structured as follows. In the next section, general methods for optimal coordination of directional overcurrent relays is discussed. Then, a proposed method for identifying primary-backup relay pairs and defining constraints for these pairs in a system where relays are sparsely placed is presented. Next, the proposed method is applied in combination with GA to solve the optimal relay coordination problem. Results are presented for three-phase settings and per-phase settings in a system with unbalanced loading. Errors are analyzed and discussed for the three-phase approximation of the unbalanced system. Lastly, results are summarized, and conclusions and future work are discussed.

\subsection{Novel Contributions of This Work}

This work focuses on distribution systems. Prior research has primarily focused on coordination of systems which have relays placed at each line in a system. However, this is more of an academic practice and is impractical in a distribution network due to cost constraints. In this paper, a method is proposed to algebraically identify which relays act to back up other relays. Additionally, per-phase relay settings in digital relays are evaluated against standard 3-phase settings. There is no current standard for per-phase relay settings and this functionality is oft overlooked in cases where per-phase settings are available as in the SEL-751. Comparisons are made to identify the benefits and detriments of each. A GA is used to solve the problems, but the choice of GA is only used for convenience due to the lack of integer programming capability in other optimization methods available in MATLAB. The GA has been used extensively used in research to solve the optimal coordination problem. The use of GA itself is not an innovation of this paper. It is simply a common tool used to solve a common problem such as the quadratic formula or the Pythagorean Theorem. This paper focuses on standard relay curves and only directional overcurrent relays. The reason for this is to find the most cost-effective protection scheme for a distribution network. Other protection schemes will increase the cost of the system and are, thus, not considered as are beyond the intended scope of this paper.

\subsection{Scope and Limitations of Presented Work}

The work developed in this paper focuses on distribution networks. In such networks, cost is a primary concern. Therefore, relays are sparsely placed. As an additional costsavings measure, the lowest cost relays to achieve an acceptable level of protection are utilized. Therefore, this paper focuses on directional overcurrent relays due to their low initial cost investments along with minimal hardware requirements (only current transformers required).

Additionally, this paper focuses on systems in which fault currents are inverter limited. Therefore, fault currents will be substantially lower than for conventional generation where 
natural laws determine the allowable level of fault currents. In such cases, fault current levels may be barely above the maximum load. Therefore, clearance of a fault becomes a power loss problem instead of an equipment damage problem. Therefore, more leeway can be granted in the time required to clear a fault.

\section{General Methods for Inverse Time-Overcurrent Relay Coordination}

A variety of methods have been developed over the years to tackle the problem of overcurrent (OC) relay coordination. The earlier methods implemented a trial and error approach to determine the coordination of OC relays. However, these methods required many iterations and a large amount of time to converge. Deterministic methods both linear and nonlinear have been developed. Linear programming methods solve the optimal relay coordination problem using a change of variable to linearize the problem, as outlined in Ref. [11]. Linear methods while fast and simple generally only optimize for a single variable (either TDS or pickup current). Nonlinear programming methods suggested in Ref. [12] can optimize for multiple variables. The downside to both deterministic methods is that they are dependent on the initial guess. They can become stuck in a local minimum preventing them from finding the global optimal solution [13]. In order to tackle this problem, stochastic methods capable of a global search have been developed.

Stochastic techniques have been proposed using a variety of optimization algorithms. In Ref. [14], particle swarm optimization (PSO) is used to optimize the coordination of overcurrent relays. In Ref. [15] PSO optimization is implemented and demonstrated on the IEEE 14-bus system. Relays are placed on each bus and relay TDS and pickup settings were optimized. In Ref. [16] teaching-learning-based optimization is used to optimize directional overcurrent relay settings. The method was demonstrated on the IEEE 3, 4, and 6 bus systems with relays placed on each bus of the system. A modified water cycle algorithm is proposed in Ref. [17] to optimize the directional overcurrent relay settings. The water cycle algorithm is demonstrated on the IEEE-30 bus system with relays present on each end of the lines. In Ref. [17], the TDS and the pickup setting for each relay are optimized to minimize the total operating time for all the relays in the system. A genetic algorithm-based solution is proposed in Ref. [18], where traditional OC relays are used, and TDS and pickup settings are optimized. This method is demonstrated using an 8-bus system with relays present on each end of the line. A firefly algorithm-based optimization for OC relay coordination is proposed in Ref. [19] for radial systems, optimizing for the TDS and pickup. In Ref. [19] comparisons are made between cases where one of three time-current characteristic (TCC) curves are used. In Ref. [20] a Moth-Flame optimization is used for coordination of Standard and Non-standard directional OC relays. Using the Moth-Flame optimization, the pickup current, TDS, TOC are optimized. The TOC for a time-overcurrent relay takes the general form of Equation (1):

$$
T=\operatorname{TDS}\left(\frac{k}{M^{\alpha}-P}+c\right)+B,
$$

where $T$ is the operating time; TDS is the time dial settings; $M$ is the multiples of the pickup current; and $k, \alpha, c$, and $B$ are parameters specific to the type of relay curve or hardware in use. Equation (1) only applies and the relay will only operate if $M^{\alpha}>P$.

In Ref. [21], the problem of optimal relay coordination is considered with a new constraint on the multiples of pickup for improving the coordination of directional OC relays in microgrids. A variable upper bound is used for the multiples of pickup for improving the coordination of directional OC relays in microgrids. The variable upper bound allows the TOC to be modified to a definite time at different multiples of pickup for each device allowing for each relay to have a customized TOC. In Ref. [22], a genetic algorithm-based coordination optimization is used to coordinate relays with the additional constraints proposed in Ref. [21]. The pickup setting the TDS and pickup setting multiples are considered as optimization variables. The proposed method is tested on a benchmark (international electrotechnical commission) IEC microgrid for multiple microgrid operating 
modes. In Ref. [20], nonstandard relay TOCs are considered by letting the parameters $k$ and $\alpha$ of Equation (11) vary independently during the optimization process. This is ideal, but it may be beyond the capabilities of the relay being considered. The method is demonstrated on a 15-bus system with directional relays present at each end of the lines in the system. This method proposed in his paper focus on standard overcurrent relay characteristics. However, for a more in-depth discussion of custom relay settings in digital relays, the reader is referred to [20-23].

In Ref. [24] a genetic algorithm-based coordination optimization is proposed for a system with distributed generation using directional OC relays. The pickup, TDS, and three types of TOC curves are considered. A single TOC curve is considered system-wide for the 3 different relay TOCs. TOC is not considered as an optimization variable for this case. The proposed approach is demonstrated on the IEEE-14 bus system with added generation and relays present at each end of the line. Three cases are considered with a different TOC curve for each case. In Ref [25] a genetic algorithm-based coordination optimization is proposed for an industrial power system. The pickup and TDS are considered as optimization variable, devices with different TOC curves are considered however the TOC setting for each device is predetermined. In Ref. [26] the coordination of directional OC relays in microgrids is carried out for grid-connected and islanded modes while considering different IEC characteristic curves for each relay. The pickup, TDS and TOC are considered as optimization variables, three different IEC curves are used for TOC. In Ref. [27] the coordination of directional OC relays in microgrids is carried similarly to [26]. However, both IEC and IEEE curves are utilized as part of the optimization. In both Ref. [26] and Ref. [27] genetic algorithm is used to carry out the optimization. A comparison of a select few optimization techniques is provided in Ref. [28], comparing the results and the time to convergence for each method. The comparison shows that the methods compared have negligible differences in the fitness value with GA converging the fastest.

Most of the papers discussed in this section focus on balanced systems with relays placed on every line. However, the methods introduced in this paper may be applied to both fully protected systems with relays on each line and systems where relays are sparsely placed throughout the system. Additionally, literature primarily focuses on the optimization of directional OC relays from a three-phase perspective. The relay settings are based on the maximum or average, load and fault currents of the three phases. The pickup settings and TDS are optimized based on these values. Modern relays such as the SEL-751, can be set in per-phase mode allowing for greater flexibility in selecting settings for the relays. This paper focuses on the application of such relay capabilities. MATLAB's global optimization toolbox is used to solve the MINLP presented in this paper. The GA is chosen out of convenience because it is the only method in the toolbox which allows for integer settings for the MINLP. General discrete settings are not directly allowed. Therefore, the discrete variables (TDS) were converted to integers using a simple multiplier.

\section{Proposed Method}

The first step in setting up the required MINLP is to identify the primary and backup relays in the system. These will be refereed to henceforth as primary-backup pairs. If a primary-backup pair is properly coordinated, the backup will only operate after a delay if the primary relay fails to operate. This failure may be in the primary relay itself or in breaker it is controlling. Note that a primary of on pair could be the secondary of a completely different pair as will be seen shortly. Identifying such pairs is simple to do visually for a small system. However, this may be difficult to impossible for larger systems. For the proposed method, a graph representation is utilized. Each bus is represented by a node and each branch element is represented by an edge. This method may be applied to individual phase lines or 3-phase lines. The proposed method is summarized as follows:

(1) Identify all source buses;

(2) Identify all leaves; 
(3) Identify all paths starting at source buses and terminating at leaves (Shortest path algorithms may be applied for this);

(4) Determine whether each edge has a relay present;

(5) Ignore each edge not having a relay present and read the relay pairs from left to right. The right-left ordering of relay "coordinates" remains unchanged;

(6) Delete any repeated primary-backup pairs.

Define the relay between buses $i$ and $j$ as $i j$. Additionally, define a matrix $\Lambda$ for which:

$$
\Lambda_{i j}= \begin{cases}1, & \text { if relay present on } i j . \\ 0, & \text { if relay not present on } i j .\end{cases}
$$

A flow chart of the proposed method is shown in Figure 1.

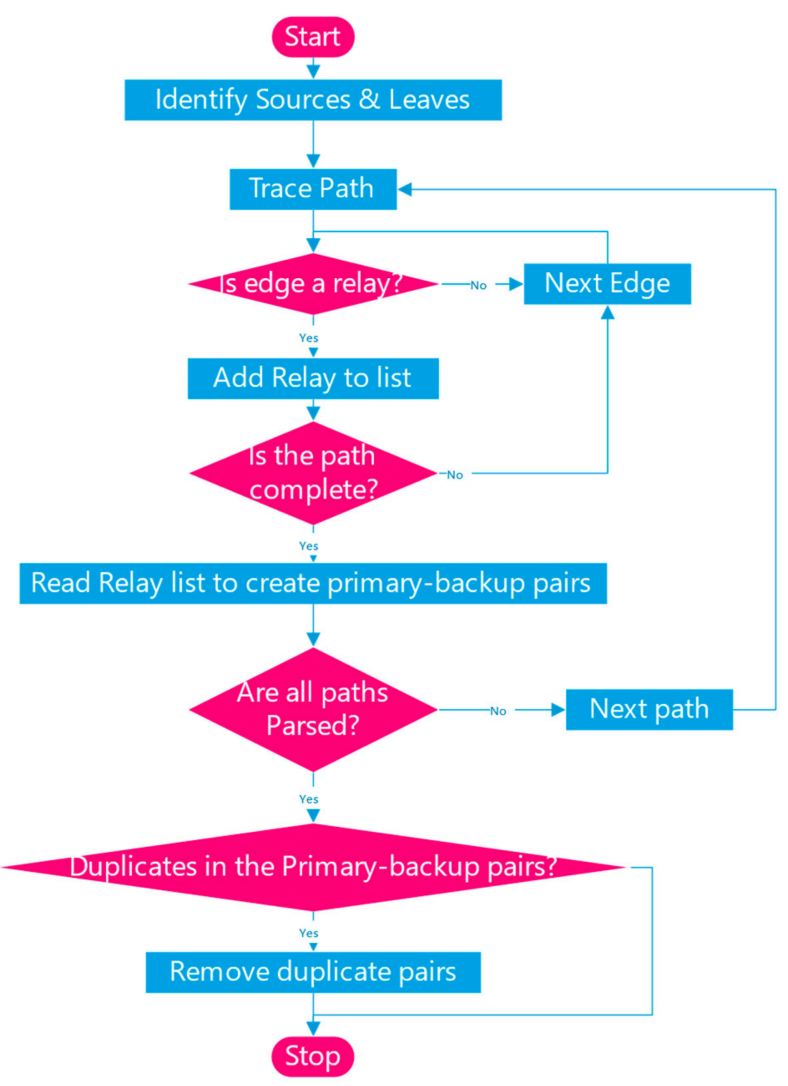

Figure 1. Proposed Method for relay coordination.

For clarity, a small example is presented here. Consider the small system show in Figure 2.

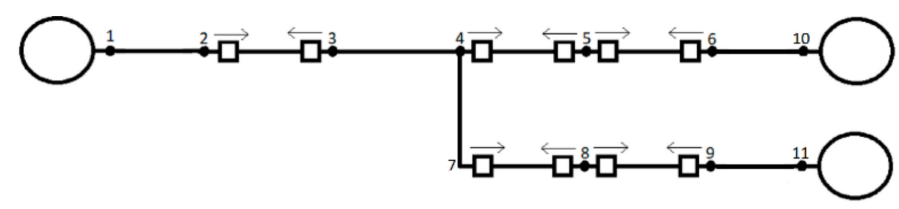

Figure 2. Simple 11-bus example system.

(1) Source buses: $1,10,11$

(2) Leaves: $1,10,11$

(3) Paths:
(a) 1-2-3-4-5-6-10
(b) $\quad 1-2-3-4-7-8-9-11$ 

(c) $10-6-5-4-3-2-1$
(d) $\quad 10-6-5-4-7-8-9-11$
(e) $\quad 11-9-8-7-4-3-2-1$
(f) $\quad 11-9-8-7-4-5-6-10$

(4) ' $\sim$ ' represents relay present and ' - ' represents not
(a) 1-2 3-4 5 6-10
(b) 1-2 3-4-7 8 9-11
(c) 10-6 5 4-3 2-1
(d) 10-6 5 4-7 8 9-11
(e) 11-9 8 7-4-3 2-1
(f) 11-9 8 7-4 5 6-10

(5) The initial pairs are given below in Table 1.

Table 1. Initial Relay Pairs.

\begin{tabular}{ccc}
\hline Primary & Backup & Path \\
\hline $5-6$ & $4-5$ & $\mathrm{a}$ \\
$4-5$ & $2-3$ & $\mathrm{a}$ \\
$7-8$ & $2-3$ & $\mathrm{~b}$ \\
$8-9$ & $7-8$ & $\mathrm{c}$ \\
$7-8$ & $5-4$ & $\mathrm{c}$ \\
$5-4$ & $6-5$ & $\mathrm{c}$ \\
$3-2$ & $5-4$ & $\mathrm{~d}$ \\
$5-4$ & $6-5$ & $\mathrm{~d}$ \\
$3-2$ & $8-7$ & $\mathrm{e}$ \\
$8-7$ & $9-8$ & $\mathrm{e}$ \\
$5-6$ & $4-5$ & $\mathrm{f}$ \\
$4-5$ & $8-7$ & $\mathrm{f}$ \\
$8-7$ & $9-8$ & $\mathrm{f}$ \\
\hline
\end{tabular}

(6) Table 1 reduces to Table 2 below.

Table 2. Reduced Relay Pairs and Inequality Constraints.

\begin{tabular}{ccc}
\hline Primary & Backup & Path \\
\hline $4-5$ & $2-3$ & $\mathrm{a}$ \\
$7-8$ & $2-3$ & $\mathrm{~b}$ \\
$8-9$ & $7-8$ & $\mathrm{c}$ \\
$7-8$ & $5-4$ & $\mathrm{c}$ \\
$5-4$ & $6-5$ & $\mathrm{c}$ \\
$3-2$ & $5-4$ & $\mathrm{~d}$ \\
$3-2$ & $8-7$ & $\mathrm{e}$ \\
$5-6$ & $4-5$ & $\mathrm{f}$ \\
$4-5$ & $8-7$ & $\mathrm{f}$ \\
$8-7$ & $9-8$ & $\mathrm{f}$ \\
\hline
\end{tabular}

In Step 6, 10 inequality constraints are defined. However, note that there is no guarantee that each relay will observe fault level current. Let $M_{i j}$ be the multiples of pickup current for relay $i j . M_{i j}$ is defined as the ratio of the fault current magnitude to the pickup current magnitude

$$
M_{i j}=\frac{\left|I_{i j}^{f}\right|}{\left|I_{i j}^{\text {pickup }}\right|},
$$

where $I_{i j}^{f}$ is the fault current and $I_{i j}^{p i c k u p}$ is the pickup current. If $M_{i j} \leq 1$ for either the primary or back up relay, the associated inequality constraint is omitted from the 
MINLP because it cannot operate according to Equation (1). CTI denotes the coordination time interval.

For the coordination problem considered, the MINLP is as follows:

$$
\begin{gathered}
\text { Minimize } \sum \sum T_{i j}^{\text {low } \Omega}+\sum \sum T_{i j}^{\text {high } \Omega} \\
\text { s.t. } \\
T_{a b}^{\text {low } \Omega} \geq T_{c d}^{\text {low } \Omega}+C T I, \forall\left\{a, b, c, d \mid M_{a b}^{\text {low } \Omega}>1, M_{c d}^{\text {low }} \Omega>1\right\} \\
T_{a b}^{\text {high } \Omega} \geq T_{c d}^{\text {high } \Omega}+C T I, \quad \forall\left\{a, b, c, d \mid M_{a b}^{\text {high } \Omega}>1, M_{c d}^{\text {high } \Omega}>1\right\} \\
(a, b) \in \operatorname{Pr} \\
(c, d) \in B a \\
\operatorname{TDS}_{i j} \in\{0.5,0.51, \ldots 14.99,15\} \\
\Gamma_{i j} \in\{1,2,3,4,5\}
\end{gathered}
$$

where $T_{i j}^{\text {low } \Omega}$ and $T_{i j}^{\text {high } \Omega}$ are the low and high resistance fault operating times, respectively, for relay $(i, j)$ as defined by (11). $P r$ and $B a$ are the set of primary and back up relays, respectively. $M_{i j}^{\text {low } \Omega}$ and $M_{i j}^{\text {high } \Omega}$ are multiples of the pickup current for the low resistance and high resistance faults, respectively. If all of the relays have the same time overcurrent characteristic (TOC), the high resistance term of (3) and the entirety of (6) may be omitted. For the computations in this paper, the SEL-751 is modeled which has a granularity of 0.01 for the TDS. For the results in this paper, steps of 0.1 are used for the TDS to reduce the size of the search space for the purpose of speeding up the optimization. The variable $\Gamma_{i j}$ represents the TOC setting for relay $i j$. The time-overcurrent characteristic for the overcurrent relay is given by

$$
\mathrm{T}_{i j}=\operatorname{TDS}_{i j}\left(\frac{k}{M^{\alpha}-P}+c\right)+B .
$$

where $\Gamma_{i j}$ is an integer variable as summarized below in Table 3. The parameters $k, c$, and $\alpha$ of (11) are changed depending on value of the integer variable $\Gamma_{i j}$ so that only standard relay TOCs are considered. For three-phase settings, all present phases of a line are required to have the same relay settings. However, for per-phase settings phases may be set on and individual basis. The current state of the art is three-phase settings. However, the SEL-751 digital relay which is in common use has the capability to choose relay settings on a per-phase basis. This option is currently underutilized, and its application is explored in depth in the results section of this paper.

Table 3. Relay time-overcurrent characteristic summary for the SEL-751 relay.

\begin{tabular}{cccccccc}
\hline $\boldsymbol{\Gamma}_{\boldsymbol{i} j}$ & Relay Type & Description & $\boldsymbol{k}$ & $\boldsymbol{c}$ & $\boldsymbol{\alpha}$ & $\boldsymbol{P}$ & $\boldsymbol{B}$ \\
\hline 1 & $\mathrm{U} 1$ & moderately inverse & 0.0104 & 0.0226 & 0.02 & 1 & 0 \\
2 & $\mathrm{U} 2$ & inverse & 5.95 & 0.018 & 2 & 1 & 0 \\
3 & $\mathrm{U} 3$ & very inverse & 3.88 & 0.0963 & 2 & 1 & 0 \\
4 & $\mathrm{U} 4$ & extremely inverse & 5.67 & 0.0352 & 2 & 1 & 0 \\
5 & $\mathrm{U} 5$ & short-time inverse & 0.00342 & 0.00262 & 0.02 & 1 & 0 \\
\hline
\end{tabular}

\section{Results}

The proposed algorithm is applied to 2 of the 4 topologies listed in Table 4 for the modified IEEE 123-bus. The system was modified with 3-phase PV added to buses 8, 18, $28,48,61,79,95,100$, and 108. The power rating of each is, respectively, 500, 700, 500, $1000,500,500,1000,500$, and $500 \mathrm{kVA}$. Each PV inverter is current limited to $1.4 \mathrm{pu}$. That is, the controls of each inverter limit the current output to $40 \%$ above its rated value to 
avoid overheating and potential damage of the costly inverter. The lower fault resistance is $0.001 \Omega$ and the upper fault resistance is $1 \Omega$. Three phase, line-line and single line to ground faults were simulated. The pickup for each relay is set to $125 \%$ of the steady state current for each line. One hundred and twenty-five percent is chosen as a middle ground between the $100 \%$ full load current and the $140 \%$ current limit of the inverter so that the relay can start to react before the inverter controls curtail the current and it's no longer sinusoidal. The CTI (coordination time interval) is set to $0.25 \mathrm{~s}$. Switch topologies 1 and 2 are considered as described in Table 4. The Modified IEEE 123-bus is shown in Figure 3.

Table 4. Switch Topologies. 1 means that the switch is on and 0 means that the switch is off.

\begin{tabular}{ccccccccc}
\hline Topology \# & $\mathbf{1 5 0 r - 1 4 9}$ & $\mathbf{1 3 - 1 5 2}^{\mathbf{1}}$ & $\mathbf{1 8 - 1 3 5 ^ { \mathbf { 1 } }}$ & $\mathbf{6 0 - 1 6 \mathbf { 1 } ^ { \mathbf { 1 } }}$ & $\mathbf{9 7 - 1 9 7}$ & $\mathbf{6 1 - 6 1} \mathbf{s}$ & $\mathbf{1 5 1 - 3 0 0 ~}^{\mathbf{1}}$ & $\mathbf{5 4 - 9 4}$ \\
\hline 1 & 1 & 0 & 1 & 1 & 1 & 1 & 1 & 0 \\
2 & 1 & 1 & 0 & 1 & 1 & 1 & 1 & 0 \\
3 & 1 & 1 & 1 & 0 & 1 & 1 & 0 \\
4 & 1 & 1 & 1 & 1 & 1 & 1 & 0 & 0 \\
\hline
\end{tabular}

${ }^{1}$ Tie lines that can be switched on or off.

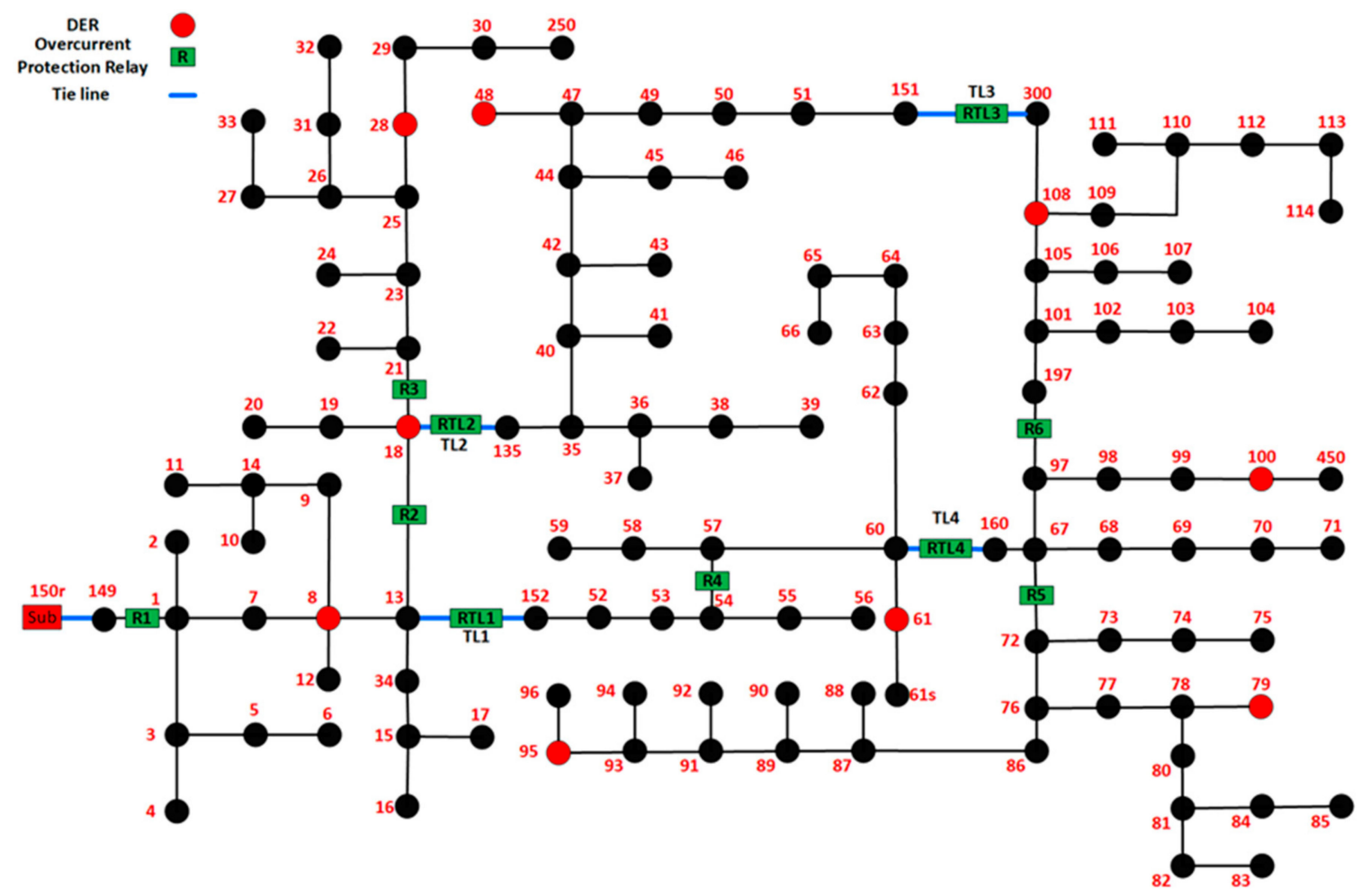

Figure 3. Modified IEEE 123-bus test case. The relays are marked with green boxes and the PV is marked with red dots. Tie lines are highlighted in blue. R denotes a relay on a permanent line and RTL denotes a relay on a tie line.

\subsection{Three-Phase Coordination Results}

A GA is used to compute the optimal three-phase relay settings with the following additional constraints:

(a) Maximum phase fault currents are considered;

(b) Pickup on each phase is $125 \%$ of maximum steady state across phases;

(c) Time dial settings are the same across all phases;

(d) Relay type is the same across all three phases.

The genetic algorithm function in MATLAB does not allow for equality constraints. However, the equality constraints imposed by (c) and (d) are enforced by considering the maximum and minimum fault currents across all phases simultaneously. These constraints 
allow the solution to consider the actual capability of the 3-phase relay. The relay will trip all three phases if any one phase exceeds the operation threshold. These settings are summarized in Table 5 and coordination results for the three-phase settings are shown in Table 6 for topology 1 .

Table 5. IEEE 123-topology 1: Three-phase settings from GA.

\begin{tabular}{ccc}
\hline Relay & TDS & Relay Type \\
\hline $13-18$ & 8.1 & U1: moderately inverse (OC) \\
$135-18$ & 1.6 & U3: very inverse (OC) \\
$151-300$ & 9.3 & U3: very inverse (OC) \\
$160-60$ & 4.1 & U3: very inverse (OC) \\
$18-13$ & 2.7 & U5: short-time inverse (OC) \\
$18-135$ & 7.2 & U2: inverse (OC) \\
$18-21$ & 3.6 & U3: very inverse (OC) \\
$197-97$ & 4.2 & U1: moderately inverse (OC) \\
$300-151$ & 2.3 & U3: very inverse (OC) \\
$57-54$ & 0.7 & U4: extremely inverse (OC) \\
$67-72$ & 2.3 & U4: extremely inverse (OC) \\
$97-197$ & 3.3 & U3: very inverse (OC) \\
$149-1$ & 13.2 & U1: moderately inverse (OC) \\
$72-67$ & 5.4 & U1: moderately inverse (OC) \\
\hline
\end{tabular}

Table 6. IEEE 123 topology 1: Coordination results for three-phase relay settings. Relay pairs with a coordination gap of higher than $2.0 \mathrm{~s}$ are marked in red.

\begin{tabular}{cccccccc}
\hline Primary & Backup & $\boldsymbol{T}_{\text {gap }}^{0.001 \Omega}(\boldsymbol{s})$ & $\boldsymbol{T}_{\text {gap }}^{1.0 \Omega}(\boldsymbol{s})$ & $\boldsymbol{M}_{0.001 \Omega}^{\text {prim }}$ & $\boldsymbol{M}_{0.001 \Omega}^{\text {back }}$ & $\boldsymbol{M}_{1.0 \Omega}^{\text {prim }}$ & $\boldsymbol{M}_{1.0 \Omega}^{\text {back }}$ \\
\hline $13-18$ & $149-1$ & 1.43 & 3.01 & 10.12 & 8.77 & 3.31 & 2.90 \\
$135-18$ & $300-151$ & 0.53 & 4.35 & 2.80 & 2.74 & 1.31 & 1.30 \\
$151-300$ & $18-135$ & 0.64 & 1.96 & 13.63 & 10.01 & 5.54 & 4.06 \\
$160-60$ & $197-97$ & 0.51 & 0.92 & 35.33 & 13.11 & 15.48 & 5.30 \\
$160-60$ & $72-67$ & 3.17 & 10.73 & 35.33 & 2.24 & 15.48 & 1.29 \\
$18-13$ & $135-18$ & 0.50 & 1.74 & 2.27 & 2.79 & 1.03 & 1.15 \\
$18-135$ & $13-18$ & 0.51 & 0.97 & 16.50 & 10.12 & 5.62 & 3.31 \\
$18-21$ & $13-18$ & 1.66 & 3.39 & 61.34 & 9.54 & 25.19 & 3.20 \\
$18-21$ & $135-18$ & 0.79 & 7.57 & 61.34 & 2.70 & 25.19 & 1.34 \\
$197-97$ & $151-300$ & 0.32 & 1.45 & 14.09 & 10.58 & 6.09 & 4.54 \\
$300-151$ & $97-197$ & 0.33 & 1.26 & 2.79 & 3.05 & 1.67 & 1.75 \\
$57-54$ & $160-60$ & 0.39 & 0.44 & 35.95 & 28.50 & 17.77 & 14.02 \\
$67-72$ & $197-97$ & 0.79 & 0.98 & 16.39 & 13.19 & 7.18 & 5.80 \\
$97-197$ & $72-67$ & 1.71 & 4.17 & 3.09 & 2.27 & 1.94 & 1.36 \\
\hline
\end{tabular}

Tables 7 and 8 show the settings and coordination for topology 2. $T_{\text {gap }}^{0.001 \Omega}$ and $T_{\text {gap }}^{1 \Omega}$ are the operating time gaps between the primary and backup relays for the $0.001 \Omega$ and $1 \Omega$ faults, respectively. $M_{0.001 \Omega}^{\text {prim }}$ and $M_{1.0 \Omega}^{\text {prim }}$ are the multiples of pickup seen by the primary relays for the $0.001 \Omega$ and $1.0 \Omega$ faults, respectively. $M_{0.001 \Omega}^{\text {back }}$ and $M_{1.0 \Omega}^{\text {back }}$ are the multiples of pickup seen by the backup relays for the $0.001 \Omega$ and $1.0 \Omega$ faults, respectively. It can be seen in Tables 6 and 8 that all coordination gaps are larger than required CTI of $0.25 \mathrm{~s}$. No upper bound is placed on the coordination gaps in the optimization setup. This is because attempting the predict and impose an upper limit on the coordination gap can degrade convergence causing the GA to arrive at an infeasible solution. This is especially true in the cases presented where PV curtailment can result in maximum fault currents of only 1.4 times the steady state current out of the inverters. 
Table 7. IEEE 123 topology 2: Three-phase settings from GA.

\begin{tabular}{ccc}
\hline Relay & TDS & Relay Type \\
\hline $13-152$ & 9.7 & U2: inverse (OC) \\
$13-18$ & 8.5 & U1: moderately inverse (OC) \\
$152-13$ & 3.7 & U3: very inverse (OC) \\
$160-60$ & 6.2 & U3: very inverse (OC) \\
$18-21$ & 4.9 & U3: very inverse (OC) \\
$197-97$ & 3.3 & U4: extremely inverse (OC) \\
$300-151$ & 7.4 & U5: short-time inverse (OC) \\
$54-57$ & 12.6 & U3: very inverse (OC) \\
$57-54$ & 3.9 & U2: inverse (OC) \\
$60-160$ & 9.1 & U3: very inverse (OC) \\
$67-72$ & 2.2 & U3: very inverse (OC) \\
$97-197$ & 4.1 & U2: inverse (OC) \\
$149-1$ & 9.4 & U1: moderately inverse (OC) \\
$72-67$ & 4.5 & U3: very inverse (OC) \\
$151-300$ & 3.5 & U4: extremely inverse (OC) \\
\hline
\end{tabular}

Table 8. IEEE 123 topology 2: Coordination results for three-phase relay settings. Relay pairs with a coordination gap of higher than $2.0 \mathrm{~s}$ are marked in red.

\begin{tabular}{cccccccc}
\hline Primary & Backup & $T_{\text {gap }}^{0.001 \Omega}(s)$ & $T_{\text {gap }}^{1.0 \Omega}(s)$ & $\boldsymbol{M}_{0.001 \Omega}^{\text {prim }}$ & $\boldsymbol{M}_{0.001 \Omega}^{\text {back }}$ & $\boldsymbol{M}_{1.0 \Omega}^{\text {prim }}$ & $\boldsymbol{M}_{1.0 \Omega}^{\text {back }}$ \\
\hline $13-152$ & $149-1$ & 0.34 & 1.08 & 20.06 & 10.65 & 6.47 & 3.32 \\
$13-18$ & $149-1$ & 0.86 & 2.41 & 23.69 & 8.83 & 8.79 & 3.02 \\
$13-18$ & $152-13$ & 1.22 & 28.53 & 23.69 & 2.64 & 8.79 & 1.21 \\
$152-13$ & $57-54$ & 1.63 & 0.51 & 2.93 & 2.88 & 1.16 & 1.25 \\
$160-60$ & $197-97$ & 0.28 & 24.70 & 2.66 & 2.23 & 1.48 & 1.19 \\
$160-60$ & $72-67$ & 0.41 & 72.79 & 2.66 & 2.20 & 1.48 & 1.09 \\
$18-21$ & $13-18$ & 1.09 & 1.72 & 65.03 & 22.56 & 25.21 & 8.47 \\
$197-97$ & $151-300$ & 1.52 & 31.92 & 2.27 & 2.07 & 1.26 & 1.14 \\
$300-151$ & $97-197$ & 0.41 & 0.59 & 24.37 & 17.65 & 11.28 & 8.11 \\
$54-57$ & $13-152$ & 0.57 & 0.72 & 15.22 & 15.36 & 5.30 & 5.48 \\
$57-54$ & $160-60$ & 0.97 & 17.50 & 2.89 & 2.59 & 1.45 & 1.27 \\
$60-160$ & $54-57$ & 0.43 & 1.12 & 13.48 & 12.95 & 4.98 & 4.75 \\
$67-72$ & $197-97$ & 4.72 & 33.17 & 24.13 & 2.21 & 9.84 & 1.25 \\
$67-72$ & $60-160$ & 0.89 & 2.17 & 24.13 & 12.09 & 9.84 & 4.81 \\
$97-197$ & $60-160$ & 0.33 & 1.48 & 23.46 & 12.15 & 9.83 & 4.81 \\
$97-197$ & $72-67$ & 4.38 & 54.03 & 23.46 & 2.17 & 9.83 & 1.15 \\
\hline
\end{tabular}

From Tables 5 and 7 , it can be seen that several directional relay settings are not set. For topology 1 relays 60-160, 21-18, 54-57, and 1-149 are not set, 54-57 is not set because there is no source to supply fault current in that direction. Remaining relays are not set because they do not see fault currents higher than pickup for any fault considered. The pickup was chosen as $125 \%$ of the maximum steady state current. The lowest acceptable pickup current must be greater than the maximum steady state across the three phases. Anything less will result in false trips during steady state operation. In preprocessing, relays not experiencing fault level currents are omitted to avoid a guaranteed failure of the GA search to find a feasible solution. Any relays not set are effectively deemed unnecessary because they do not ever experience fault level currents. If they are already placed in the system, they should be either reallocated to a more useful position or set to the fastest available relay setting is this is not possible. Reallocation of such relays can allow for additional cost savings in lieu of purchasing additional relays and breakers. Similarly, for topology 2 relays $21-18$ and 18-13 are not set. Figure 4 shows the primary operating times for the relays in topology 1 . Several relays have a high operating time with a maximum operating time of about $3.5 \mathrm{~s}$ for relay 72-67. Figure 5 shows the primary operating times for the relays in topology 2. In topology 2 many relays have a high operating time with 
a maximum operating time of about $6.1 \mathrm{~s}$ for relay 151-300. These higher times are due to low fault current from the current limited PV sources. In such cases, fault currents do not pose an imminent danger of damage to equipment. For such faults, the only potential determent to the system is a temporary increase in power losses.

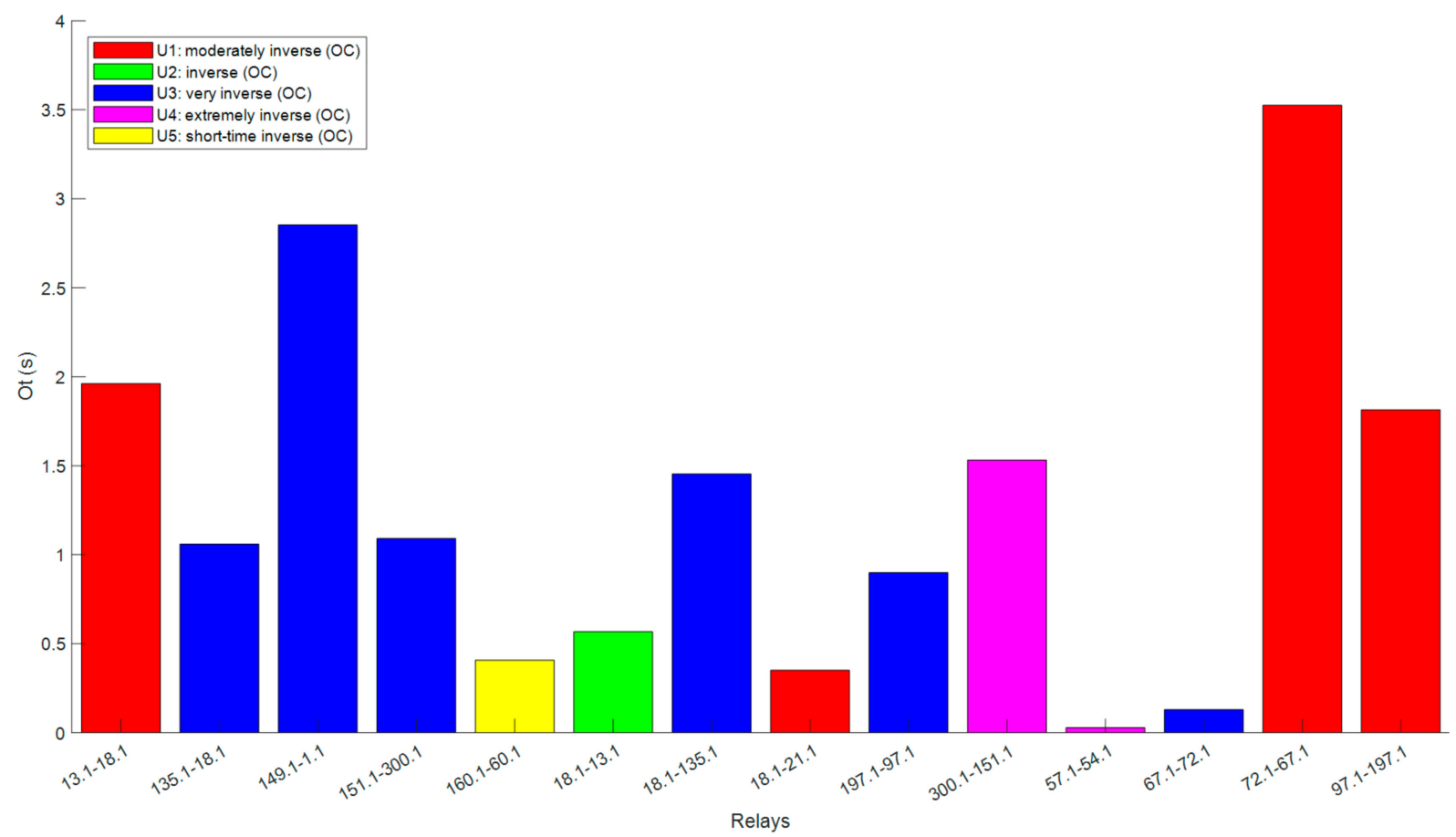

Figure 4. IEEE 123 topology 1 relay operating times when acting as primary using 3 phase settings.

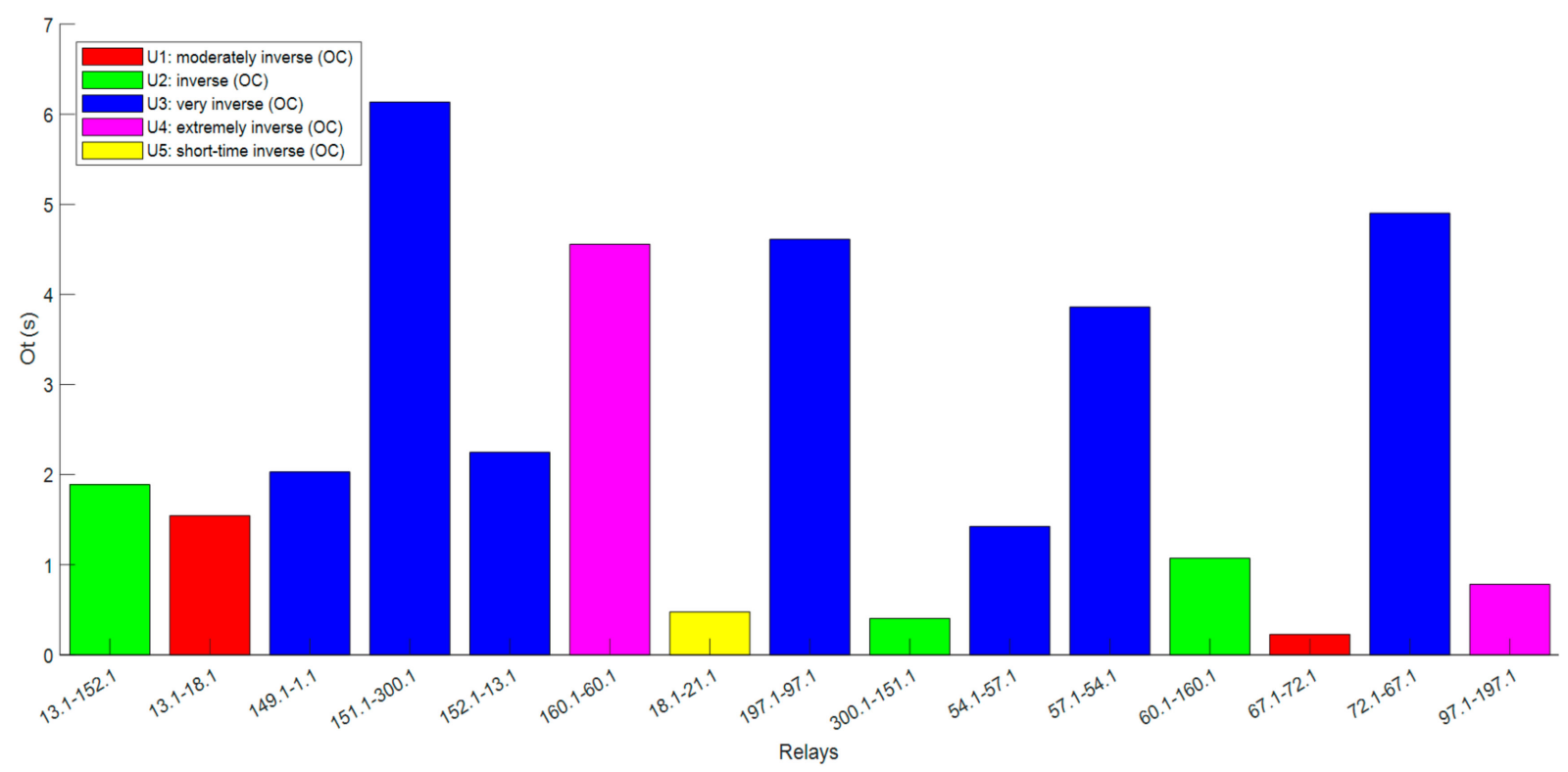

Figure 5. IEEE 123 topology 2 relay operating times when acting as primary using three-phase settings.

\subsection{Per-Phase Coordination Results}

The per-phase coordination results are summarized in Tables 9 and 10 for topology 1 ; and Tables 11 and 12 for topology 2. For the bus names in these tables, 0.1, 0.2, and 0.3 denote phases $\mathrm{A}, \mathrm{B}$, and $\mathrm{C}$, respectively. Note that in each of the relays, there are different settings among phases. GA is used to solve the optimal relay coordination problem due to the discrete nature of the problem. The downside to this methodology is that the degree 
of variation in phase settings may differ from one GA run to another if more than one feasible solution exists. However, if the relay type is fixed for reach relay, a deterministic derivative-based method may be utilized instead assuming continuous time dial settings. This will allow for more consistency in settings differences among phases. It can be seen in Table 8 that the coordination gaps are all above the lower limit of $0.25 \mathrm{~s}$. An upper bound may be set to avoid longer relay operating times. However, such additional constraints will both increase computation time and degrade convergence. That is, a feasible solution either may not exist, or the search space may be too large for GA to efficiently find one if it does exist. This balance of reducing coordination time while avoiding degraded convergence will be a topic of future work. It can be seen in Tables 9 and 11 that, like the three-phase case, several reverse direction relay settings are not set because they do not experience fault currents higher than pickup for any fault. Figures 6 and 7 show the primary operating times for the relays with per-phase settings in topology 1 and topology 2 , respectively. Several relays have a high operating time with a maximum operating time of about $3 \mathrm{~s}$ for relay 72.2-67.2 in topology 1, $5.3 \mathrm{~s}$ for relay 72.3-67.3 in topology 2.

Table 9. IEEE 123 topology 1 per-phase relay settings from GA.

\begin{tabular}{|c|c|c|}
\hline Relay & TDS & Relay Type \\
\hline $13.1-18.1$ & 5.7 & U2: inverse (OC) \\
\hline $13.2-18.2$ & 5.5 & U2: inverse (OC) \\
\hline $13.3-18.3$ & 9.9 & U3: very inverse (OC) \\
\hline $135.1-18.1$ & 1.1 & U4: extremely inverse (OC) \\
\hline $135.2-18.2$ & 2.9 & U5: short-time inverse (OC) \\
\hline $135.3-18.3$ & 1.6 & $\mathrm{U} 1:$ moderately inverse (OC) \\
\hline 151.1-300.1 & 8.2 & U3: very inverse (OC) \\
\hline $151.2-300.2$ & 8 & U3: very inverse (OC) \\
\hline $151.3-300.3$ & 8.1 & U3: very inverse (OC) \\
\hline $160.1-60.1$ & 4 & U3: very inverse (OC) \\
\hline $160.2-60.2$ & 5.2 & U3: very inverse (OC) \\
\hline $160.3-60.3$ & 12 & U4: extremely inverse (OC) \\
\hline $18.1-13.1$ & 1.4 & U5: short-time inverse (OC) \\
\hline $18.1-135.1$ & 9.9 & $\mathrm{U} 3$ : very inverse $(\mathrm{OC})$ \\
\hline $18.1-21.1$ & 2 & U4: extremely inverse (OC) \\
\hline $18.2-13.2$ & 0.7 & U5: short-time inverse (OC) \\
\hline $18.2-135.2$ & 5.2 & $\mathrm{U} 2$ : inverse $(\mathrm{OC})$ \\
\hline $18.2-21.2$ & 6.5 & U4: extremely inverse (OC) \\
\hline $18.3-13.3$ & 0.5 & U5: short-time inverse (OC) \\
\hline $18.3-135.3$ & 8.9 & U3: very inverse (OC) \\
\hline $18.3-21.3$ & 5.6 & U4: extremely inverse (OC) \\
\hline 197.1-97.1 & 7.1 & U3: very inverse $(\mathrm{OC})$ \\
\hline $197.2-97.2$ & 6.7 & U3: very inverse (OC) \\
\hline $197.3-97.3$ & 6.7 & U3: very inverse (OC) \\
\hline $300.1-151.1$ & 3.3 & U3: very inverse (OC) \\
\hline $300.2-151.2$ & 1.1 & U3: very inverse (OC) \\
\hline $300.3-151.3$ & 1.6 & U3: very inverse (OC) \\
\hline $57.1-54.1$ & 0.9 & U4: extremely inverse (OC) \\
\hline $57.2-54.2$ & 3.2 & U4: extremely inverse (OC) \\
\hline $57.3-54.3$ & 5.6 & U4: extremely inverse (OC) \\
\hline $67.1-72.1$ & 7.1 & U4: extremely inverse (OC) \\
\hline $67.2-72.2$ & 4.8 & U4: extremely inverse (OC) \\
\hline $67.3-72.3$ & 2.1 & $\mathrm{U} 2$ : inverse $(\mathrm{OC})$ \\
\hline 97.1-197.1 & 3.6 & U2: inverse (OC) \\
\hline $97.2-197.2$ & 3 & U3: very inverse (OC) \\
\hline $97.3-197.3$ & 2.9 & U3: very inverse (OC) \\
\hline
\end{tabular}


Table 10. IEEE 123 topology 1: Coordination results for per-phase settings. Relay pairs with a coordination gap of higher than $2.0 \mathrm{~s}$ are marked in red.

\begin{tabular}{|c|c|c|c|c|c|c|c|}
\hline Primary & Backup & $T_{\text {gap }}^{0.001 \Omega}(s)$ & $T_{g a p}^{1.0 \Omega}(s)$ & $M_{0.001 \Omega}^{\text {prim }}$ & $M_{0.001 \Omega}^{b a c k}$ & $M_{1.0 \Omega}^{\text {prim }}$ & $M_{1.0 \Omega}^{\text {back }}$ \\
\hline $13.1-18.1$ & $18.1-149.1$ & 0.26 & 2.38 & 10.12 & 8.77 & 3.31 & 2.90 \\
\hline $13.2-18.2$ & $18.2-149.2$ & 0.31 & 1.91 & 10.20 & 8.82 & 3.31 & 2.90 \\
\hline $13.3-18.3$ & $18.3-149.3$ & 1.48 & 0.70 & 9.80 & 8.50 & 3.31 & 2.90 \\
\hline $135.1-18.1$ & $18.1-300.1$ & 1.34 & 10.09 & 2.80 & 2.74 & 1.31 & 1.30 \\
\hline $135.2-18.2$ & $18.2-300.2$ & 0.28 & 4.13 & 2.80 & 2.74 & 1.42 & 1.34 \\
\hline $135.3-18.3$ & $18.3-300.3$ & 0.27 & 5.66 & 2.80 & 2.74 & 1.42 & 1.34 \\
\hline 151.1-300.1 & 300.1-18.1 & 0.38 & 1.58 & 13.63 & 10.01 & 5.54 & 4.06 \\
\hline $151.2-300.2$ & $300.2-18.2$ & 0.29 & 1.12 & 14.40 & 10.60 & 5.54 & 4.06 \\
\hline $151.3-300.3$ & $300.3-18.3$ & 0.25 & 1.25 & 13.78 & 10.12 & 5.54 & 4.06 \\
\hline $160.1-60.1$ & 60.1-197.1 & 0.45 & 1.25 & 35.33 & 13.11 & 15.48 & 5.30 \\
\hline $160.1-60.1$ & $60.1-72.1$ & 3.13 & 21.16 & 35.33 & 2.26 & 15.48 & 1.29 \\
\hline $160.2-60.2$ & $60.2-197.2$ & 0.26 & 1.02 & 30.16 & 13.67 & 15.48 & 5.30 \\
\hline $160.2-60.2$ & $60.2-72.2$ & 1.35 & 10.19 & 30.16 & 2.26 & 15.48 & 1.29 \\
\hline $160.3-60.3$ & 60.3-197.3 & 0.30 & 0.90 & 33.74 & 13.71 & 15.48 & 5.30 \\
\hline $160.3-60.3$ & $60.3-72.3$ & 2.22 & 14.86 & 33.74 & 2.26 & 15.48 & 1.29 \\
\hline 18.1-13.1 & $13.1-135.1$ & 0.66 & 10.33 & 2.27 & 2.79 & 1.03 & 1.15 \\
\hline 18.1-135.1 & 135.1-13.1 & 0.27 & 2.23 & 16.50 & 10.12 & 5.62 & 3.31 \\
\hline $18.1-21.1$ & $21.1-13.1$ & 1.33 & 4.60 & 61.34 & 9.54 & 25.19 & 3.20 \\
\hline $18.1-21.1$ & $21.1-135.1$ & 0.96 & 7.77 & 61.34 & 2.70 & 25.19 & 1.34 \\
\hline $18.2-13.2$ & $13.2-135.2$ & 0.34 & 0.84 & 2.27 & 2.79 & 1.10 & 1.26 \\
\hline $18.2-135.2$ & $135.2-13.2$ & 0.26 & 2.33 & 16.59 & 10.20 & 5.62 & 3.31 \\
\hline $18.2-21.2$ & $21.2-13.2$ & 1.12 & 4.24 & 60.63 & 9.53 & 25.19 & 3.20 \\
\hline $18.2-21.2$ & $21.2-135.2$ & 0.26 & 1.21 & 60.63 & 2.70 & 25.19 & 1.39 \\
\hline $18.3-13.3$ & $13.3-135.3$ & 0.73 & 2.67 & 2.27 & 2.79 & 1.10 & 1.26 \\
\hline $18.3-135.3$ & $135.3-13.3$ & 0.36 & 2.83 & 15.97 & 9.80 & 5.62 & 3.31 \\
\hline $18.3-21.3$ & $21.3-13.3$ & 1.21 & 4.86 & 58.66 & 9.17 & 25.19 & 3.20 \\
\hline $18.3-21.3$ & $21.3-135.3$ & 0.66 & 2.28 & 58.66 & 2.70 & 25.19 & 1.39 \\
\hline 197.1-97.1 & $97.1-151.1$ & 0.25 & 0.96 & 14.09 & 10.58 & 6.09 & 4.54 \\
\hline $197.2-97.2$ & $97.2-151.2$ & 0.26 & 0.99 & 14.81 & 11.11 & 6.09 & 4.54 \\
\hline 197.3-97.3 & 97.3-151.3 & 0.27 & 1.02 & 14.74 & 11.07 & 6.09 & 4.54 \\
\hline 300.1-151.1 & 151.1-97.1 & 1.04 & 3.48 & 2.79 & 3.05 & 1.67 & 1.75 \\
\hline $300.2-151.2$ & $151.2-97.2$ & 0.90 & 3.40 & 2.88 & 3.16 & 1.67 & 1.75 \\
\hline 300.3-151.3 & $151.3-97.3$ & 0.54 & 2.07 & 2.85 & 3.11 & 1.67 & 1.75 \\
\hline $57.1-54.1$ & $54.1-160.1$ & 0.37 & 0.42 & 35.95 & 28.50 & 17.77 & 14.02 \\
\hline $57.2-54.2$ & $54.2-160.2$ & 0.40 & 0.43 & 32.18 & 25.37 & 17.77 & 14.02 \\
\hline $57.3-54.3$ & $54.3-160.3$ & 0.29 & 0.47 & 35.48 & 28.16 & 17.77 & 14.02 \\
\hline $67.1-72.1$ & 72.1-197.1 & 0.44 & 0.48 & 16.39 & 13.19 & 7.18 & 5.80 \\
\hline $67.2-72.2$ & 72.2-197.2 & 0.52 & 0.74 & 17.29 & 13.85 & 7.18 & 5.80 \\
\hline $67.3-72.3$ & 72.3-197.3 & 0.36 & 0.82 & 17.23 & 13.90 & 7.18 & 5.80 \\
\hline 97.1-197.1 & 197.1-72.1 & 0.36 & 8.13 & 3.09 & 2.27 & 1.94 & 1.36 \\
\hline $97.2-197.2$ & 197.2-72.2 & 0.34 & 3.77 & 3.21 & 2.26 & 1.94 & 1.36 \\
\hline $97.3-197.3$ & $197.3-72.3$ & 1.14 & 7.61 & 3.14 & 2.27 & 1.94 & 1.36 \\
\hline
\end{tabular}


Table 11. IEEE 123 topology 2: Per-phase relay settings from GA.

\begin{tabular}{|c|c|c|}
\hline Relay & TDS & Relay Type \\
\hline $13.1-152.1$ & 5.2 & U2: inverse (OC) \\
\hline $13.1-18.1$ & 3.2 & $\mathrm{U} 1$ : moderately inverse (OC) \\
\hline $13.2-152.2$ & 6.9 & $\mathrm{U} 1:$ moderately inverse (OC) \\
\hline $13.2-18.2$ & 3.3 & $\mathrm{U} 1:$ moderately inverse (OC) \\
\hline $13.3-152.3$ & 5.9 & U1: moderately inverse (OC) \\
\hline $13.3-18.3$ & 11.1 & U4: extremely inverse (OC) \\
\hline 152.1-13.1 & 2.4 & $\mathrm{U} 1$ : moderately inverse (OC) \\
\hline $152.2-13.2$ & 4.8 & U5: short-time inverse (OC) \\
\hline $152.3-13.3$ & 1.1 & U3: very inverse $(\mathrm{OC})$ \\
\hline $160.1-60.1$ & 4.5 & U3: very inverse (OC) \\
\hline $160.2-60.2$ & 2.5 & $\mathrm{U} 1$ : moderately inverse (OC) \\
\hline $160.3-60.3$ & 1.9 & $\mathrm{U} 2$ : inverse $(\mathrm{OC})$ \\
\hline $18.1-21.1$ & 7.3 & U5: short-time inverse (OC) \\
\hline $18.2-21.2$ & 8.2 & U5: short-time inverse (OC) \\
\hline $18.3-21.3$ & 2.3 & U5: short-time inverse (OC) \\
\hline 197.1-97.1 & 3.4 & U3: very inverse $(\mathrm{OC})$ \\
\hline $197.2-97.2$ & 3.8 & $\mathrm{U} 1:$ moderately inverse (OC) \\
\hline 197.3-97.3 & 2.6 & U3: very inverse $(\mathrm{OC})$ \\
\hline 300.1-151.1 & 0.7 & U4: extremely inverse (OC) \\
\hline $300.2-151.2$ & 2.4 & U4: extremely inverse (OC) \\
\hline $300.3-151.3$ & 2.3 & U4: extremely inverse (OC) \\
\hline $54.1-57.1$ & 7.1 & $\mathrm{U} 3$ : very inverse $(\mathrm{OC})$ \\
\hline $54.2-57.2$ & 8.2 & U3: very inverse (OC) \\
\hline $54.3-57.3$ & 6.8 & U3: very inverse (OC) \\
\hline $57.1-54.1$ & 3.5 & U3: very inverse (OC) \\
\hline $57.2-54.2$ & 2.2 & $\mathrm{U} 1:$ moderately inverse (OC) \\
\hline $57.3-54.3$ & 4 & $\mathrm{U1}$ : moderately inverse (OC) \\
\hline $60.1-160.1$ & 8.1 & U5: short-time inverse (OC) \\
\hline $60.2-160.2$ & 5.5 & U3: very inverse $(\mathrm{OC})$ \\
\hline $60.3-160.3$ & 8.4 & U5: short-time inverse (OC) \\
\hline $67.1-72.1$ & 0.5 & U3: very inverse $(\mathrm{OC})$ \\
\hline $67.2-72.2$ & 3.7 & U5: short-time inverse (OC) \\
\hline $67.3-72.3$ & 4.1 & U5: short-time inverse (OC) \\
\hline 97.1-197.1 & 2.7 & U3: very inverse $(\mathrm{OC})$ \\
\hline $97.2-197.2$ & 9 & U4: extremely inverse (OC) \\
\hline $97.3-197.3$ & 6 & U5: short-time inverse (OC) \\
\hline 149.1-1.1 & 6.7 & $\mathrm{U} 2$ : inverse $(\mathrm{OC})$ \\
\hline $149.2-1.2$ & 6.7 & U1: moderately inverse (OC) \\
\hline $149.3-1.3$ & 8.8 & $\mathrm{U} 1$ : moderately inverse (OC) \\
\hline $72.1-67.1$ & 3.3 & U3: very inverse $(\mathrm{OC})$ \\
\hline $72.2-67.2$ & 1.5 & U3: very inverse $(\mathrm{OC})$ \\
\hline $72.3-67.3$ & 7.7 & $\mathrm{U} 1:$ moderately inverse (OC) \\
\hline 151.1-300.1 & 3.4 & U3: very inverse $(\mathrm{OC})$ \\
\hline $151.2-300.2$ & 3.8 & $\mathrm{U} 1:$ moderately inverse (OC) \\
\hline $151.3-300.3$ & 2.3 & U3: very inverse $(\mathrm{OC})$ \\
\hline
\end{tabular}


Table 12. IEEE 123 topology 2: Coordination results for per-phase settings. Relay pairs with coordination gaps greater than $2.0 \mathrm{~s}$ are marked in red.

\begin{tabular}{|c|c|c|c|c|c|c|c|}
\hline Primary & Backup & $T_{\text {gap }}^{0.001 \Omega}(s)$ & $T_{\text {gap }}^{1.0 \Omega}(s)$ & $M_{0.001 \Omega}^{\text {prim }}$ & $M_{0.001 \Omega}^{\text {back }}$ & $M_{1.0 \Omega}^{\text {prim }}$ & $M_{1.0 \Omega}^{\text {back }}$ \\
\hline $13.1-152.1$ & 149.1-1.1 & 0.55 & 3.48 & 20.06 & 10.65 & 6.47 & 3.32 \\
\hline $13.1-18.1$ & $149.1-1.1$ & 1.14 & 5.29 & 23.69 & 8.83 & 8.79 & 3.02 \\
\hline 13.1-18.1 & 152.1-13.1 & 0.75 & 5.67 & 23.69 & 2.64 & 8.79 & 1.21 \\
\hline $13.2-152.2$ & $149.2-1.2$ & 0.26 & 1.05 & 20.81 & 11.08 & 6.47 & 3.23 \\
\hline $13.2-18.2$ & $149.2-1.2$ & 1.11 & 2.49 & 23.68 & 8.89 & 8.79 & 2.95 \\
\hline $13.2-18.2$ & $152.2-13.2$ & 0.26 & 2.53 & 23.68 & 2.60 & 8.79 & 1.28 \\
\hline $13.3-152.3$ & $149.3-1.3$ & 0.96 & 2.24 & 19.81 & 10.56 & 6.47 & 3.29 \\
\hline $13.3-18.3$ & $149.3-1.3$ & 1.78 & 3.14 & 22.71 & 8.52 & 8.79 & 2.97 \\
\hline $13.3-18.3$ & $152.3-13.3$ & 0.29 & 5.71 & 22.71 & 2.67 & 8.79 & 1.28 \\
\hline $152.1-13.1$ & $57.1-54.1$ & 0.99 & 16.02 & 2.93 & 2.88 & 1.16 & 1.25 \\
\hline $152.2-13.2$ & $57.2-54.2$ & 0.35 & 1.11 & 2.93 & 2.88 & 1.30 & 1.31 \\
\hline $152.3-13.3$ & $57.3-54.3$ & 1.37 & 1.46 & 2.93 & 2.88 & 1.33 & 1.34 \\
\hline $160.1-60.1$ & 197.1-97.1 & 0.35 & 17.23 & 2.66 & 2.23 & 1.48 & 1.19 \\
\hline $160.1-60.1$ & $72.1-67.1$ & 0.33 & 53.53 & 2.66 & 2.20 & 1.48 & 1.09 \\
\hline $160.2-60.2$ & $197.2-97.2$ & 1.12 & 3.50 & 2.58 & 2.23 & 1.48 & 1.34 \\
\hline $160.2-60.2$ & $72.2-67.2$ & 0.26 & 27.84 & 2.58 & 2.19 & 1.48 & 1.09 \\
\hline $160.3-60.3$ & 197.3-97.3 & 0.50 & 2.95 & 2.61 & 2.23 & 1.48 & 1.34 \\
\hline $160.3-60.3$ & $72.3-67.3$ & 2.92 & 36.91 & 2.61 & 2.20 & 1.48 & 1.09 \\
\hline $18.1-21.1$ & $13.1-18.1$ & 0.28 & 0.44 & 65.03 & 22.56 & 25.21 & 8.47 \\
\hline $18.2-21.2$ & $13.2-18.2$ & 0.27 & 0.42 & 64.30 & 22.34 & 25.21 & 8.47 \\
\hline $18.3-21.3$ & $13.3-18.3$ & 0.43 & 1.16 & 62.03 & 21.50 & 25.21 & 8.47 \\
\hline 197.1-97.1 & 151.1-300.1 & 0.83 & 19.91 & 2.27 & 2.07 & 1.26 & 1.14 \\
\hline $197.2-97.2$ & $151.2-300.2$ & 0.30 & 5.26 & 2.27 & 2.07 & 1.36 & 1.18 \\
\hline $197.3-97.3$ & $151.3-300.3$ & 0.25 & 3.68 & 2.27 & 2.07 & 1.43 & 1.29 \\
\hline 300.1-151.1 & $97.1-197.1$ & 0.26 & 0.37 & 24.37 & 17.65 & 11.28 & 8.11 \\
\hline $300.2-151.2$ & $97.2-197.2$ & 0.36 & 0.91 & 25.86 & 18.72 & 11.28 & 8.11 \\
\hline $300.3-151.3$ & $97.3-197.3$ & 0.25 & 0.31 & 26.05 & 18.90 & 11.28 & 8.11 \\
\hline 54.1-57.1 & $13.1-152.1$ & 0.26 & 0.30 & 15.22 & 15.36 & 5.30 & 5.48 \\
\hline $54.2-57.2$ & $13.2-152.2$ & 0.50 & 0.27 & 16.09 & 16.22 & 5.30 & 5.48 \\
\hline $54.3-57.3$ & $13.3-152.3$ & 0.46 & 0.28 & 15.24 & 15.36 & 5.30 & 5.48 \\
\hline $57.1-54.1$ & $160.1-60.1$ & 1.32 & 15.81 & 2.89 & 2.59 & 1.45 & 1.27 \\
\hline $57.2-54.2$ & $160.2-60.2$ & 0.30 & 2.04 & 2.89 & 2.59 & 1.48 & 1.30 \\
\hline $57.3-54.3$ & $160.3-60.3$ & 0.30 & 11.33 & 2.89 & 2.59 & 1.48 & 1.30 \\
\hline $60.1-160.1$ & $54.1-57.1$ & 0.31 & 1.09 & 13.48 & 12.95 & 4.98 & 4.75 \\
\hline $60.2-160.2$ & $54.2-57.2$ & 0.32 & 0.84 & 14.22 & 13.69 & 4.98 & 4.75 \\
\hline $60.3-160.3$ & $54.3-57.3$ & 0.25 & 0.97 & 13.81 & 13.29 & 4.98 & 4.75 \\
\hline $67.1-72.1$ & 197.1-97.1 & 3.68 & 23.77 & 24.13 & 2.21 & 9.84 & 1.25 \\
\hline $67.1-72.1$ & $60.1-160.1$ & 0.51 & 0.82 & 24.13 & 12.09 & 9.84 & 4.81 \\
\hline $67.2-72.2$ & $197.2-97.2$ & 2.37 & 6.43 & 26.11 & 2.21 & 9.84 & 1.35 \\
\hline $67.2-72.2$ & $60.2-160.2$ & 0.47 & 1.21 & 26.11 & 12.50 & 9.84 & 4.81 \\
\hline $67.3-72.3$ & $197.3-97.3$ & 2.64 & 10.98 & 25.23 & 2.21 & 9.84 & 1.38 \\
\hline $67.3-72.3$ & $60.3-160.3$ & 0.36 & 0.61 & 25.23 & 12.40 & 9.84 & 4.81 \\
\hline $97.1-197.1$ & $60.1-160.1$ & 0.28 & 0.52 & 23.46 & 12.15 & 9.83 & 4.81 \\
\hline 97.1-197.1 & $72.1-67.1$ & 3.51 & 39.98 & 23.46 & 2.17 & 9.83 & 1.15 \\
\hline $97.2-197.2$ & $60.2-160.2$ & 0.27 & 0.64 & 25.40 & 12.57 & 9.83 & 4.81 \\
\hline $97.2-197.2$ & $72.2-67.2$ & 1.36 & 17.49 & 25.40 & 2.15 & 9.83 & 1.15 \\
\hline 97.3-197.3 & $60.3-160.3$ & 0.25 & 0.47 & 24.50 & 12.46 & 9.83 & 4.81 \\
\hline 97.3-197.3 & $72.3-67.3$ & 4.99 & 28.53 & 24.50 & 2.16 & 9.83 & 1.15 \\
\hline
\end{tabular}




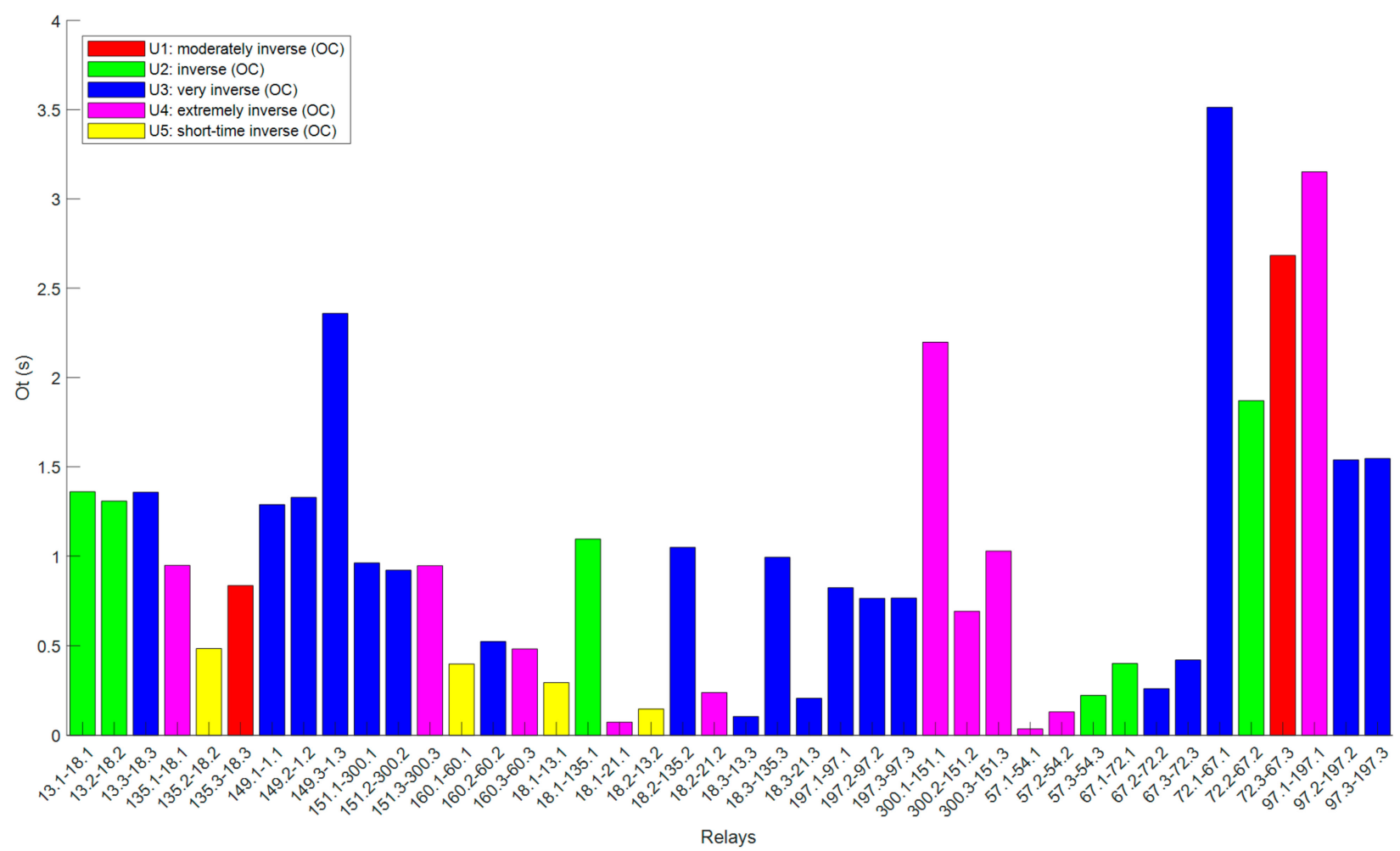

Figure 6. IEEE 123 topology 1 relay operating times when acting as a primary relay using per-phase settings.

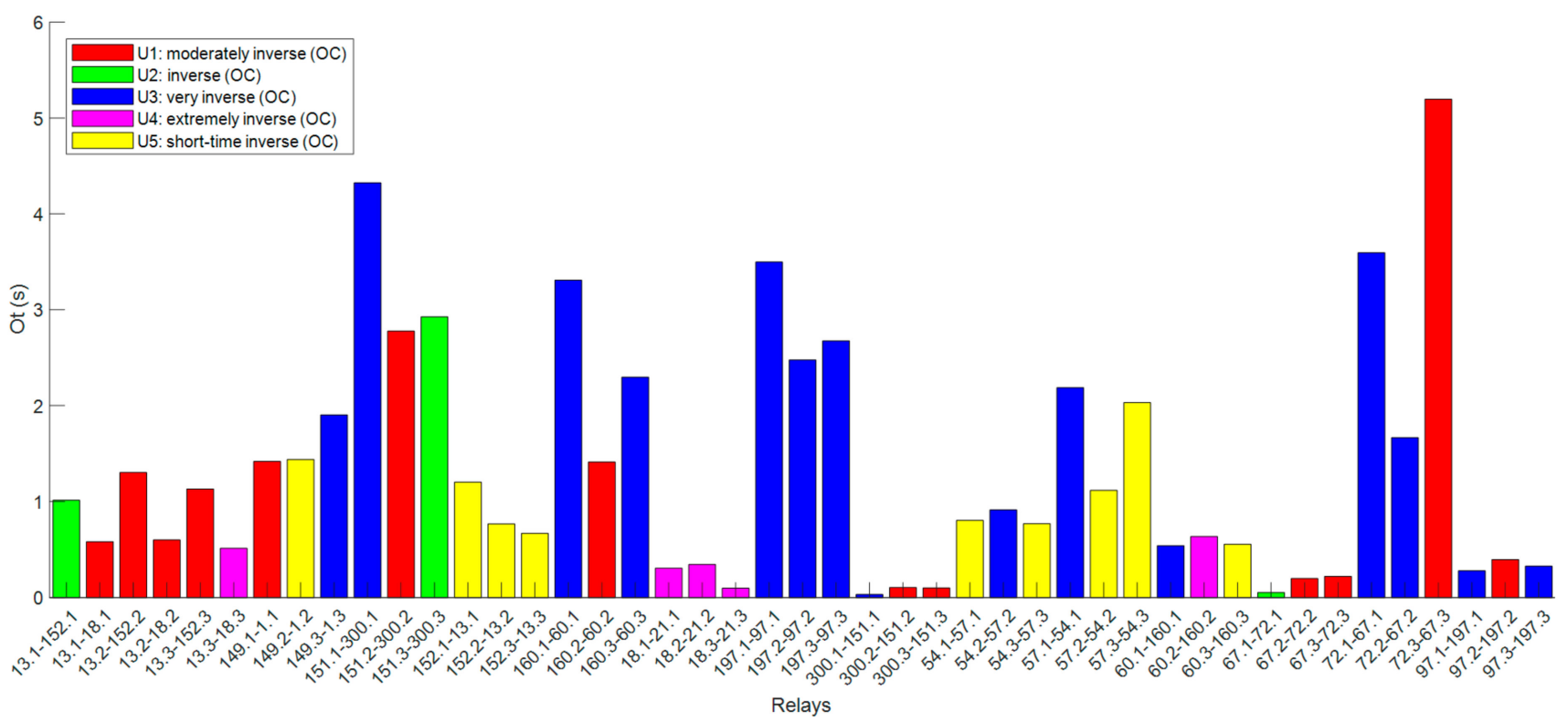

Figure 7. IEEE 123 topology 2 relay operating times when acting as primary using per-phase settings.

Due to the stochastic nature of GA, direct comparisons of operating time between the per-phase and three-phase setting for individual relays can be misleading. That is, GA is not guaranteed to converge to the same solution each time it runs unless there is only a single solution. However, certain trends can be identified. In Tables 6, 8, 10 and 12, relay pairs with coordination gaps greater than $2.0 \mathrm{~s}$ are highlighted. Additionally, looking at Figures 4-7 it can be observed that several relays have operating times higher than $1.0 \mathrm{~s}$. For the purposes of this discussion, relays with operating times greater than $1.0 \mathrm{~s}$ will be defined as slow operating. 
For the three-phase settings, approximately $57 \%$ of the relays are slow operating in topology 1; and $66 \%$ are slow operating in topology 2 . For the per-phase settings, about $38 \%$ of the relays are slow operating for topology 1 ; and about $46 \%$ are slow operating for topology 2.

For the three-phase case, the number of coordination gaps above $2.0 \mathrm{~s}$ is slightly higher at about $36 \%$ for topology 1 . In topology 2 the percentage of relays with coordination gaps greater than $2.0 \mathrm{~s}$ remains the same. For the per-phase case, approximately $26 \%$ of the relay primary-backup pairs have a coordination gaps of $2.0 \mathrm{~s}$ or greater for topology 1 . For topology 2 , the number is $34 \%$.

However, the average coordination gap observed for relays reduces from $9.20 \mathrm{~s}$ in the three-phase case to $4.50 \mathrm{~s}$ in the per-phase case for topology 2. For the cases considered, coordination gaps and operating times appear to be lower on average using the per-phase settings versus the three-phase settings. This trend is relatively consistent across multiple GA runs. However, an affirmative statement about this comparison cannot be made with rigorous proof.

The difference in operating times and coordination intervals between the per-phase and three-phase settings are primarily due to the flexibility of considering fault currents on a per-phase basis. However, this flexibility comes with the cost of greater computational burden. For the per-phase settings in IEEE 123 bus case earlier presented, the GA optimizer has 84 variables to optimize, whereas that number is reduced to about a third for the threephase case, to 28 variables in topology 1 . In topology 2 the GA must optimize 90 variables for the per phase case and 30 variables for three phase case. This difference in number of variables is also reflected in the number of nonlinear constraints for the optimization. Considering the increased complicity of the per-phase case it takes on average 3-5 time longer to compute and has a greater variability in the solution due to the stochastic nature of GA. Additionally, for balanced system such as a transmission system where the unbalance is kept at a minimum, the per-phase settings may offer no benefit as all the phases will have similar loading and fault capacity. In the cases of balanced system, the flexibility offered by the per-phase settings may be outweighed by the increased computation time and variability in the solution. Therefore, traditional three-phase settings should be utilized for such situations and per-phase settings should be used when the system has a large amount of unbalance.

\section{Conclusions}

GA was used to compute both per-phase and 3-phase relay settings for two topologies of the IEEE 123 bus system. For balanced systems or systems will low levels of unbalanced loading, the three-phase method should be utilized since it allows for faster computation times. For systems with higher levels of imbalance, per-phase settings are desirable since they offer greater flexibility leading to faster operating times and smaller coordination gaps on average.

10 GA runs were completed for both the per-phase and 3-phase settings. The variances were quite large for these repeated runs. The average time for computing the 3-phase settings was $301.34 \mathrm{~s}$ with a variance of $1994.58 \mathrm{~s}$. For the per-phase settings, the average computation time was $1219.49 \mathrm{~s}$ with a variance of 3313.14. An anecdotal conclusion can be drawn that the 3-phase settings can be consistently computed faster than the per-phase settings. However, a definitive statement cannot be made about this especially considering the stochastic nature of GA.

Although the SEL-751 has other protection options available, only inverse time overcurrent protection was utilized. Introducing other types of protection (distance, undervoltage, communication-based, etc.) could further reduce the coordination gaps so that the slower relays can operate faster. In future work, other types of protection and will also be considered. Additionally, coordination with fixed devices such as fuses and electromechanical relays has not been considered. This will be another topic for future research. 
Author Contributions: Conceptualization, R.C.M., M.J.R., A.K.S. and S.H.-M.; methodology, R.C.M., T.R.P., M.J.R. and A.K.S.; software, R.C.M., T.R.P. and M.J.R.; validation, M.J.R., T.R.P. and A.K.S.; formal analysis, R.C.M. and T.R.P.; investigation, S.H.-M.; resources, M.J.R.; data curation, S.H.M.; writing—original draft preparation, R.C.M. and T.R.P.; writing—review and editing, S.H.-M., A.K.S. and M.J.R.; visualization, R.C.M. and T.R.P.; supervision, M.J.R.; project administration, M.J.R.; funding acquisition, M.J.R. All authors have read and agreed to the published version of the manuscript.

Funding: This research was funded by U.S. Department of Energy's National Nuclear Security Administration under contract DE-NA-3525.

Institutional Review Board Statement: Not applicable.

Informed Consent Statement: Not applicable.

Data Availability Statement: Not applicable.

Acknowledgments: Sandia National Laboratories is a multi-mission laboratory managed and operated by National Technology and Engineering Solutions of Sandia, LLC., a wholly owned subsidiary of Honeywell International, Inc., for the U.S. Department of Energy's National Nuclear Security Administration under contract DE-NA-3525. This paper describes objective technical results and analysis. Any subjective views or opinions that might be expressed in the paper do not necessarily represent the views of the U.S. Department of Energy or the United States Government.

Conflicts of Interest: The authors declare no conflict of interest.

\section{References}

1. Matthews, R.C.; Hossain-McKenzie, S.; Reno, M.J. Fault Current Correction Strategies for Effective Fault Location in InverterBased Systems. In Proceedings of the IEEE Photovoltaic Specialists Conference (PVSC), Chicago, IL, USA, 16-21 June 2019.

2. Duan, J.; Zhang, K.; Cheng, L. A Novel Method of Fault Location for Single-Phase Microgrids. IEEE Trans. Smart Grid 2015, 7 , 1-11. [CrossRef]

3. Seuss, J.; Broderick, M.R.R.J.; Grijalva, S. Maximum PV Size Limited by the Impact to Distribution Protection. In Proceedings of the IEEE 42nd Photovoltaic Specialist Conference (PVSC), New Orleans, LA, USA, 14-19 June 2015.

4. Blackburn, J.L.; Domin, T.J. Protective Relaying: Principles and Applications, 4th ed.; Routledge: London, UK, 2014.

5. Std 1547-2018-IEEE Standard for Interconnection and Interoperability of Distributed Energy Resources with Associated Electric Power Systems Interfaces; Revision of IEEE Std 1547-2003; IEEE: New York, NY, USA, 2018; pp. 1-138. [CrossRef]

6. Leite, H.; Almeida, E.; Silva, N. Real-time closed-loop test to adaptive protection in a smart-grid context. In Proceedings of the 13th International Conference on Development in Power System Protection 2016 (DPSP), Edinburgh, UK, 7-10 March 2016.

7. Zhang, H.; Li, S. Design of adaptive line protection under smart grid. In Proceedings of the International Conference on Advanced Power System Automation and Protection, Beijing, China, 16-20 October 2011.

8. Venkata, S.S.; Reno, M.J.; Bower, W.; Manson, S.; Reilly, J.; Sey, G.W., Jr. Microgrid Protection: Advancing the State of the Art; Sandia National Laboratories: Albuquerque, NM, USA, 2019.

9. Hossain-McKenzie, S.S.; Piesciorovsky, E.C.; Reno, M.J.; Hambrick, J.C. Microgrid Fault Location: Challenges and Solutions; Sandia National Laboratories: Albuquerque, NM, USA, 2018.

10. Juan, L.; JingHan, H.; Hao, Z.; Feixiang, X.; ZhiQian, B.; Yip, T. Research on adaptive protection based on integrated protection. In Proceedings of the International Conference on Advanced Power System Automation and Protection, Beijing, China, 16-20 October 2011.

11. Birla, D.; Maheshwari, R.P.; Gupta, H.O.; Deep, K.; Thakur, M. Application of Random Search Technique in Directional Overcurrent Relay Coordination. Int. J. Emerg. Electr. Power Syst. 2006, 7. [CrossRef]

12. Birla, D.; Maheshwari, R.P.; Gupta, H.O. A New Nonlinear Directional Overcurrent Relay Coordination Technique, and Banes and Boons of Near-End Faults Based Approach. IEEE Trans. Power Deliv. 2006, 21, 1176-1182. [CrossRef]

13. Rajput, V.N.; Pandya, K.S. Coordination of directional overcurrent relays in the interconnected power systems using effective tuning of harmony search algorithm. Sustain. Comput. Inform. Syst. 2017, 15, 1-15. [CrossRef]

14. Mansour, M.M.; Mekhamer, S.F.; El-Kharbawe, N. A Modified Particle Swarm Optimizer for the Coordination of Directional Overcurrent Relays. IEEE Trans. Power Deliv. 2007, 22, 1400-1410. [CrossRef]

15. Zeineldin, H.; El-Saadany, E.; Salama, M. Optimal coordination of overcurrent relays using a modified particle swarm optimization. Electr. Power Syst. Res. 2006, 76, 988-995. [CrossRef]

16. Singh, M.; Panigrahi, B.; Abhyankar, A. Optimal coordination of directional over-current relays using Teaching Learning-Based Optimization (TLBO) algorithm. Int. J. Electr. Power Energy Syst. 2013, 50, 33-41. [CrossRef]

17. Korashy, A.; Kamel, S.; Youssef, A.-R.; Jurado, F. Modified water cycle algorithm for optimal direction overcurrent relays coordination. Appl. Soft Comput. 2019, 74, 10-25. [CrossRef] 
18. Razavi, F.; Abyaneh, H.A.; Al-Dabbagh, M.; Mohammadi, R.; Torkaman, H. A new comprehensive genetic algorithm method for optimal overcurrent relays coordination. Electr. Power Syst. Res. 2008, 78, 713-720. [CrossRef]

19. Chhun, P.; Priyadi, A.; Pujiantara, M.; Mahindara, V.R. Optimal Coordination of OCR with TCC Selection for Radial Industrial System Using Firefly Algorithm. In Proceedings of the International Seminar on Intelligent Technology and Its Applications (ISITIA), Surabaya, Indonesia, 22-23 July 2020.

20. Korashy, A.; Kamel, S.; Alquthami, T.; Jurado, F. Optimal Coordination of Standard and Non-Standard Direction Overcurrent Relays Using an Improved Moth-Flame Optimization. IEEE Access 2020, 8, 87378-87392. [CrossRef]

21. Saad, S.M.; El-Naily, N.; Mohamed, F.A. A new constraint considering maximum PSM of industrial over-current relays to enhance the performance of the optimization techniques for microgrid protection schemes. Sustain. Cities Soc. 2019, 44, 445-457. [CrossRef]

22. Saldarriaga-Zuluaga, S.D.; López-Lezama, J.M.; Muñoz-Galeano, N. Optimal Coordination of Overcurrent Relays in Microgrids Considering a Non-Standard Characteristic. Energies 2020, 13, 922. [CrossRef]

23. Hill, D.J.; Bruehler, L.W.; Bohrer, C.J. Why wait? System-wide benefits from custom overcurrent relay characteristics. In Proceedings of the Industry Applications Society 56th Annual Petroleum and Chemical Industry Conference, Anaheim, CA, USA, 14-16 September 2009.

24. Tiwari, R.; Singh, R.K.; Choudhary, N.K. Optimal Coordination of Dual Setting Directional Over Current Relays in Microgrid With Different Standard Relay Characteristics. In Proceedings of the IEEE 9th Power India International Conference (PIICON), Sonepat, India, 28 February-1 March 2020.

25. Chen, C.-R.; Lee, C.-H.; Chang, C.-J. Optimal overcurrent relay coordination in power distribution system using a new approach. Int. J. Electr. Power Energy Syst. 2013, 45, 217-222. [CrossRef]

26. Alam, M.N. Overcurrent protection of AC microgrids using mixed characteristic curves of relays. Comput. Electr. Eng. 2019, 74, 74-88. [CrossRef]

27. Srinivas, S.T.P.; Swarup, K.S. A New Mixed Integer Linear Programming Formulation for Protection Relay Coordination Using Disjunctive Inequalities. IEEE Power Energy Technol. Syst. J. 2019, 6, 104-112. [CrossRef]

28. Niranjan, P.; Choudhary, N.K.; Singh, R.K. Performance Analysis of Different Optimization Techniques on Protection Coordination of Overcurrent Relay in Microgrid. In Proceedings of the International Conference on Electrical, Electronics and Computer Engineering (UPCON), Aligarh, India, 8-10 November 2019. 